\title{
Who fans the flames of Alzheimer's disease brains? Misfolded tau on the crossroad of neurodegenerative and inflammatory pathways
}

\author{
Norbert Zilka ${ }^{1,2}$, Zuzana Kazmerova ${ }^{1}$, Santosh Jadhav ${ }^{1}$, Peter Neradil ${ }^{1}$, Aladar Madari ${ }^{3}$, Dominika Obetkova ${ }^{1}$, \\ Ondrej Bugos ${ }^{1}$ and Michal Novak ${ }^{1,2^{*}}$
}

\begin{abstract}
Neurodegeneration, induced by misfolded tau protein, and neuroinflammation, driven by glial cells, represent the salient features of Alzheimer's disease (AD) and related human tauopathies. While tau neurodegeneration significantly correlates with disease progression, brain inflammation seems to be an important factor in regulating the resistance or susceptibility to AD neurodegeneration. Previously, it has been shown that there is a reciprocal relationship between the local inflammatory response and neurofibrillary lesions. Numerous independent studies have reported that inflammatory responses may contribute to the development of tau pathology and thus accelerate the course of disease. It has been shown that various cytokines can significantly affect the functional and structural properties of intracellular tau. Notwithstanding, anti-inflammatory approaches have not unequivocally demonstrated that inhibition of the brain immune response can lead to reduction of neurofibrillary lesions. On the other hand, our recent data show that misfolded tau could represent a trigger for microglial activation, suggesting the dual role of misfolded tau in the Alzheimer's disease inflammatory cascade. On the basis of current knowledge, we can conclude that misfolded tau is located at the crossroad of the neurodegenerative and neuroinflammatory pathways. Thus disease-modified tau represents an important target for potential therapeutic strategies for patients with Alzheimer's disease.
\end{abstract}

Keywords: Alzheimer's disease, Tauopathies, Neurofibrillary degeneration, Neuroinflammation, Microglia

\section{Neurodegenerative niche in the ocean of the brain inflammation}

Alzheimer's disease (AD), the major cause of dementia, is characterized by the aberrant folding of the protein tau, leading to its intracellular and extracellular accumulation and to $\beta$-amyloidosis seen as extracellular deposits of $\beta$-amyloid (A $\beta)$ in the brain parenchyma and around cerebral blood vessels [1-8]. Although it is well-documented that $A \beta$ deposition is considered to be an important inducer of the chronic inflammatory response driven by activated microglia and astrocytes [9-12], little is known about the role of misfolded tau in the neuroinflammatory cascade. In $\mathrm{AD}$, the pathological lesions of misfolded tau are present as intracellular and extracellular neurofibrillary tangles, neuropil threads and neuritic

\footnotetext{
* Correspondence: michal.novak@savba.sk

${ }^{1}$ Institute of Neuroimmunology, 84510 Bratislava, Slovak Republic Full list of author information is available at the end of the article
}

plaques [6,7]. Interestingly, several independent studies have revealed that the regional distribution and load of neurofibrillary lesions parallel the distribution of reactive microglia in AD $[13,14]$. In an extensive histopathological study published by Irina Alafuzoff's group, it was shown that ApoE genotype significantly influenced the linkage between neurofibrillary tangles (NFTs) and activated microglia. Furthermore, the authors clearly demonstrated that microglial upregulation of major histocompatibility complex class II antigen (HLA-DR) increased the duration of AD and correlated with NFT counts in sporadic cases, but not in familial ones [15].

Apparently, activated microglia were frequently present in the proximity of NFTs at early [16] and later stages of tangle formation $[14,17,18]$ (Figures $1 \mathrm{~A}$ and $1 B)$. Sheng et al. showed that the number of IL-1 $\alpha$-positive microglia and $S 100 \beta$-positive astrocytes progressively increased with NFT load, suggesting that both 


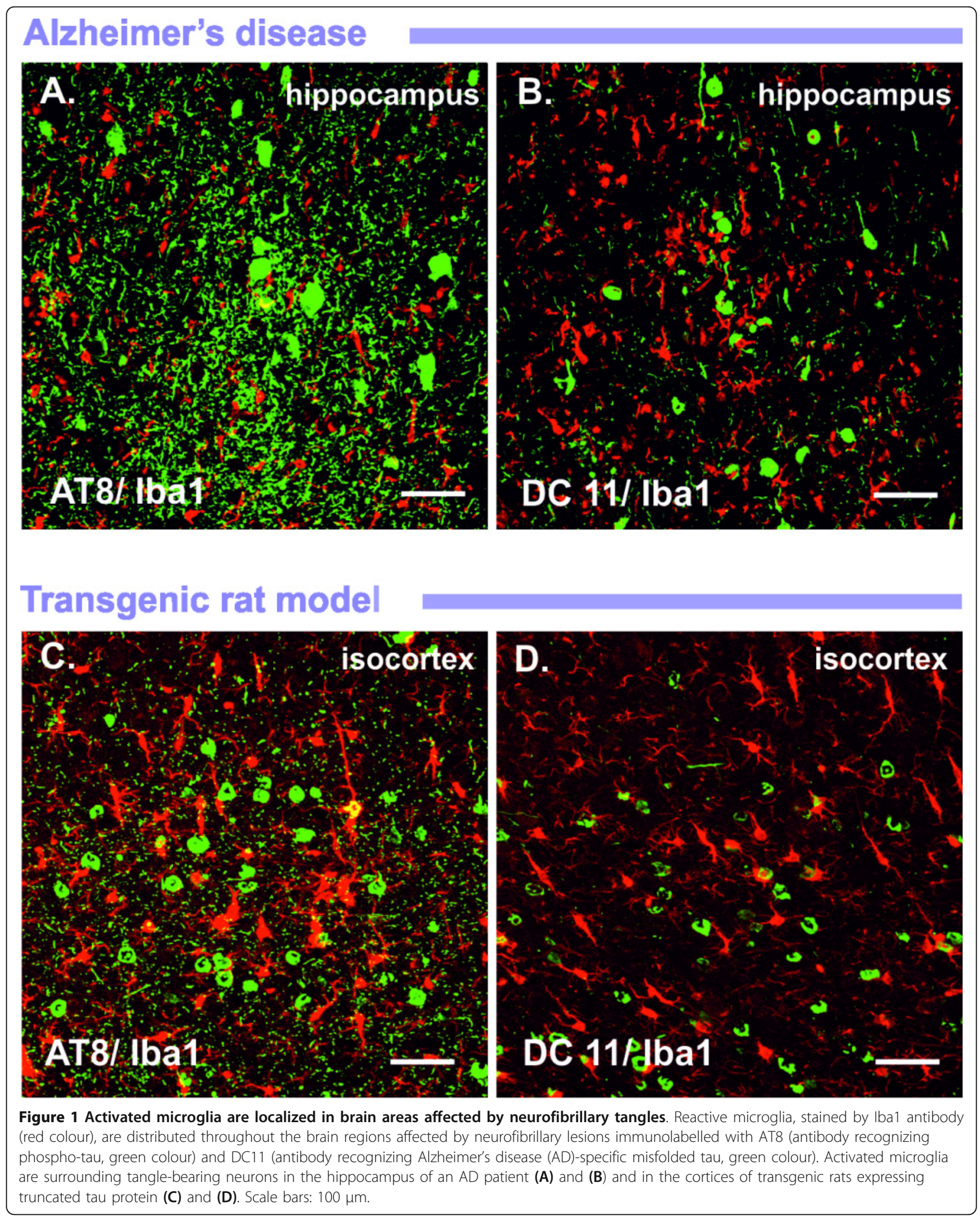


executive arms of the brain immune system, microglia and astroglia, are involved in the immune response targeting tau pathology [16]. It is noteworthy that, in the late stages of tangle development, astrocytes and microglia infiltrate extracellular "ghost" tangles and may contribute to the degradation of tau filaments $[17,19]$. Likewise, the complement proteins C1q, C3d and C4d were found to colocalize with dystrophic neurites, neuropil threads and tangle-bearing neurons. Similarly, an antibody recognizing the C5b-9 membrane attack complex stained dystrophic neurites and many tangle-bearing neurons [20,21].

It has been clearly demonstrated that microglial activation also correlates with tau lesions in other human tauopathies, such as Guam parkinsonism dementia, Pick's disease, progressive supranuclear palsy and corticobasal degeneration [22-27]. The activation of microglia linked to tau deposition has been well-documented in various transgenic rodent models expressing human mutant tau protein P301S [28,29], R406W [30], P301L [31] or disease-modified, truncated tau protein $[32,33]$. We have shown that transgenic rat lines expressing human truncated tau developed extensive neurofibrillary degeneration, either in the cortex [34] or in the brainstem [35]. The neurofibrillary pathology in the transgenic rat brain fulfils criteria for human NFTs. Importantly, the load of NFTs positively correlated with reactive microglia (Figures $1 \mathrm{C}$ and 1D) [34]. Occasionally, activated microglia were closely attached to tangle-bearing neurons (Figure 2), suggesting direct causative interconnection between tangles and reactive microglia [32]. Although there is convincing evidence that diseased, modified tau and neuroinflammation are closely linked, the precise relationship remains unclear.

\section{Immunosuppression could attenuate tau pathology}

The concept based on the premise that anti-inflammatory therapy may prevent or retard the development of $\mathrm{AD}$ originated with the discovery that neuroinflammation strongly correlates with AD and that it is associated with senile plaque pathology and NFTs [36,37]. Moreover, epidemiological studies have indicated that nonsteroidal anti-inflammatory drugs (NSAIDs) lower the risk of developing $\mathrm{AD}[38,39]$. In accord with these findings, several drugs, such as the nonselective or COX2-selective NSAIDs and glucocorticoid steroids, were studied to determine if they offer any benefits to AD patients. However, randomized controlled trials assessing COX2 inhibitors (rofecoxib and celecoxib), COX1 and COX2 inhibitors (naproxen and indomethacin) and glucocorticoids (prednisone) failed to demonstrate any beneficial effect on cognition, behaviour or activities of daily living among AD patients [37,40-43]. Furthermore, NSAIDs were not associated with reductions in the load of neuritic plaques (NPs) or NFTs in human AD brain. On the contrary, one study showed that heavy NSAID use was associated with a significant increase in NPs [44]. In contrast, it has been shown that the use of corticosteroids significantly decreased the density of NPs and NFTs in the entorhinal cortices, hippocampi and amygdalae of AD patients [45]. Similarly, immunosuppressive treatment of young transgenic mice expressing mutant tau P301S attenuated tau pathology and increased lifespan. This animal study revealed that targeted inhibition of the inflammatory response can reduce tau pathology and ameliorate disease progression [29].
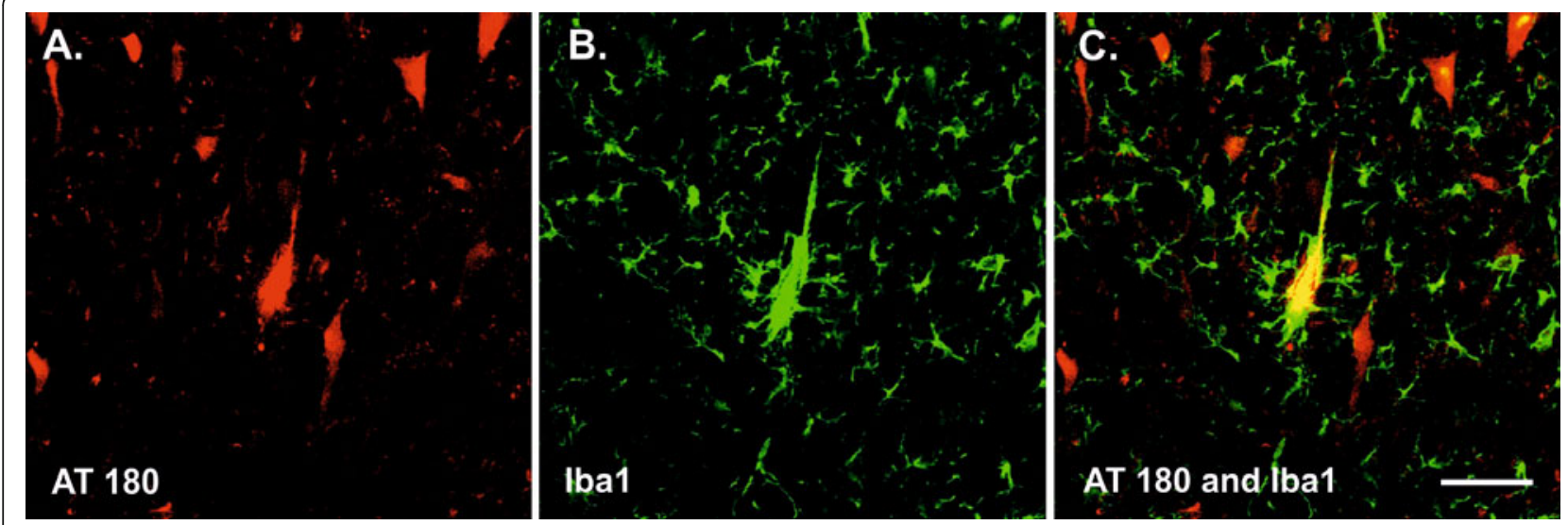

Figure 2 Colocalization of clustered microglia and neurofibrillary tangles in transgenic rat brain. Neurofibrillary tangles (NFTs) were detected with the monoclonal antibody AT180, recognizing tau protein phosphorylated at Thr231 and Ser235 (A), respectively. Activated microglia were stained with the polyclonal antibody Iba1, specific for ionized calcium-binding adaptor molecule 1 (B). Confocal study showed that some NFTs colocalized with clusters of activated microglia (C). Scale bars: $100 \mu \mathrm{m}$. 


\section{Which comes first, neurodegeneration or neuroinflammation?}

Whether microglia activation precedes neurodegeneration remains an issue of debate. Several independent studies have shown that neurofibrillary pathology and reactive microglia display the same distribution pattern in $\mathrm{AD}$. The presence of reactive microglia in brain areas affected by neurodegeneration indicates that NFT pathology can drive neuroinflammation. However, some authors have argued that reactive microglia precede tangle formation and thus can establish a template for the development of neurofibrillary degeneration. Sheffield and colleagues [14] showed that microglia occupied the greatest area in periallocortex/allocortex (hippocampus CA1, entorhinal cortex and parasubiculum), a lesser area in association cortex (superior temporal gyrus and orbitofrontal cortex) and the smallest area in primary visual and motor cortex in $\mathrm{AD}$ and in controls without AD [14]. Similar findings were described in a mouse model expressing mutated tau P301S, where microglial activation preceded tangle formation [29]. This is only one side of the story; another side points towards agerelated structural deterioration of microglial cells that may even precede tangle formation. Wolfgang Streit demonstrated that dystrophic rather than activated microglia correlated with tau lesions [46-48]. Structural and functional impairment of microglial cells may significantly affect the bidirectional communication between tangle-bearing neurons and dystrophic microglial cells. Furthermore, degeneration of microglia would necessarily be associated with a loss of their potential neuroprotective properties. In conclusion, a breakdown of communication between microglia and neurons could contribute to the onset of $\mathrm{AD}$ [46-48].

\section{Cytokine storm can finely tune tau neurodegenerative metamorphosis}

Placing cytokine responses upstream in the cascade of deleterious events that lead to tau neurodegeneration has opened new avenues in AD research. Many independent in vivo and ex vivo studies provide compelling evidence that cytokines can significantly influence the pathological modifications of tau protein. This issue was brought to light by the landmark study of Li et al. [49], who showed that reactive microglia producing proinflammatory cytokines such as IL-1 induced an increase in tau phosphorylation in primary cortical neurons. This effect was mediated via the p38 mitogen-activated protein kinase (MAPK) pathways. Similar studies supporting this notion showed that either nitric oxide (NO) or IL-6 can promote tau phosphorylation inside neuronal cells [50,51]. Recently, Lee et al. [52] reported that injections of lipopolysaccharide (LPS) into the frontal cortices and hippocampi of transgenic mice rTg4510 expressing human mutant tau P301L induced significant activation of CD45 immunoreactive microglia and increased tau phosphorylation at Ser199/202 and Ser396; however, LPS did not affect the load of silverpositive NFTs. Consistent with these findings, a subsequent study using a $3 \times \mathrm{Tg}-\mathrm{AD}$ model harbouring $\mathrm{PS} 1_{\mathrm{M} 146 \mathrm{~V}}+\mathrm{APP}_{\mathrm{KM} 670 / 671 \mathrm{NL}}+$ tau $_{\mathrm{P} 301 \mathrm{~L}}$ mutations revealed increased phosphorylation of tau (p231/235 and p202/205) in the hippocampus [53]. LPS can induce microglial activation and promote hyperphosphorylation of endogenous tau in wild-type mice as well. Increased phospho-tau levels were dependent upon TLR-4 and IL1 signalling. Moreover, tau phosphorylation was further enhanced in mice lacking the microglia-specific fractalkine receptor (CX3CR1) [54]. Interestingly, gene delivery of the proinflammatory cytokine TNF- $\alpha$ into the brains of $3 \times \mathrm{Tg}-\mathrm{AD}$ mice induced microglial activation and enhanced intracellular levels of hyperphosphorylated tau [55]. Additionally, a lifetime-based Förster energy resonance transfer (FRET) microscopy study revealed that either activated microglia producing TNF- $\alpha$ or the gliaderived cytokine TNF- $\alpha$ alone were able to induce the accumulation of tau preferentially in neurites [56]. These results strongly suggest that cytokines can significantly modify tau phosphorylation, but have limited impact on tangle formation.

Recent data cast a new light on the role of fractalkine as a key regulator of tangle development. Bhaskar and colleagues [54] showed that transgenic mice lacking CX3CR1 and expressing human tau isoforms had markedly increased numbers of tangle-bearing neurons. This contrasts with a previously published report where the same research group showed that CX3CR1 deficiency led to a reduction of $A \beta$ deposits [57]. It is important to stress, however, that amyloid lesions are located in the extracellular space and that therefore a different mechanism of microglial action could be involved in the degradation of amyloid deposits [57].

On the basis of the data reported so far, it is tempting to hypothesize that molecular dialogue between neuronal cells and microglia can significantly influence neuronal vulnerability to tangle formation. Also on the basis of these data, one could propose that the proinflammatory immune response can amplify tau phosphorylation, which can accelerate tangle formation.

\section{Genetic background modifies the neuroinflammatory response to tau neurodegeneration}

Numerous epidemiological studies have demonstrated that genetic background modifies the onset and progression of $\mathrm{AD}$ and related neurodegenerative disorders. Studies using amyloid mouse models of AD have demonstrated the importance of genetic background for the transgenic 


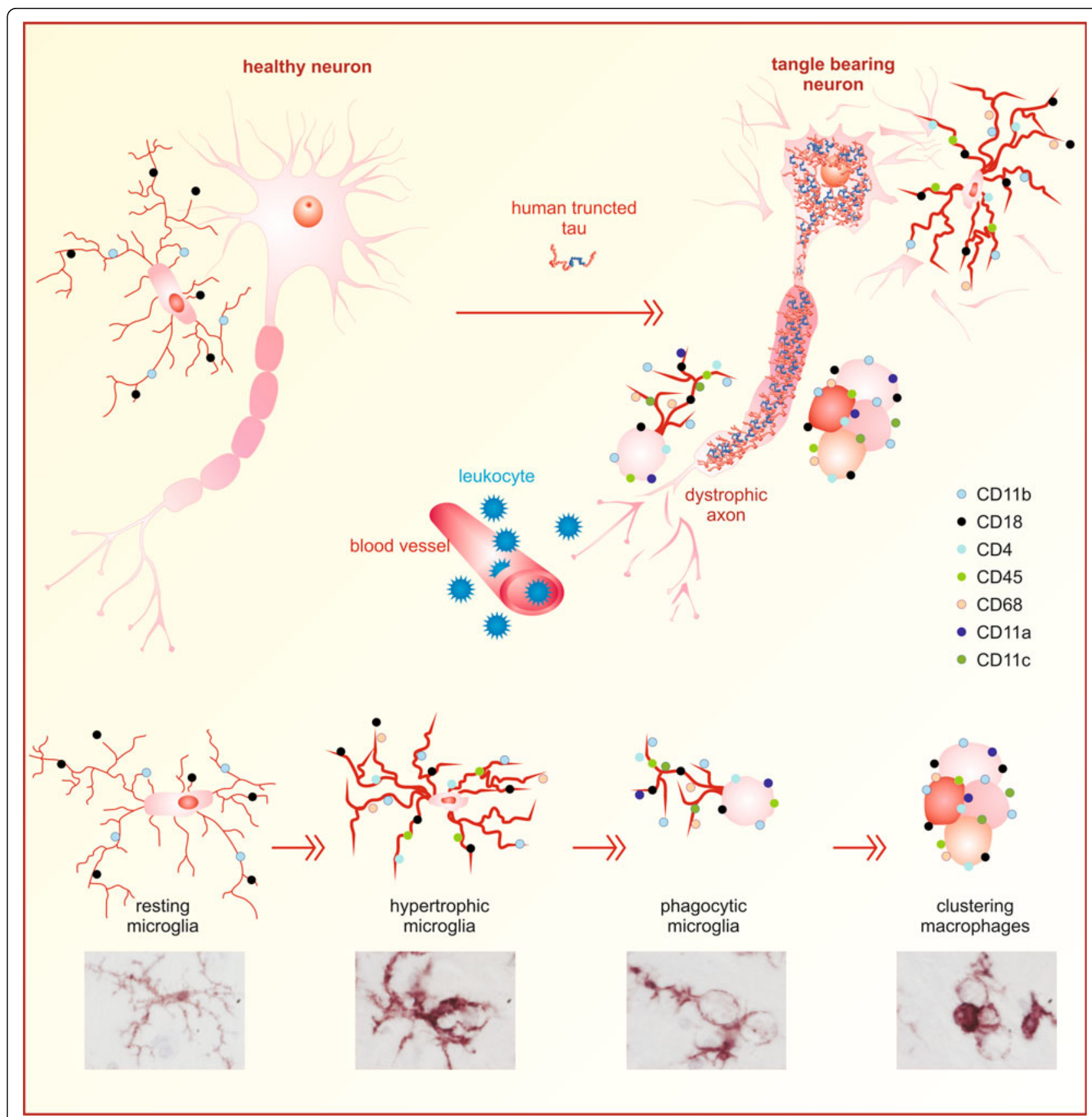

Figure 3 Functional plasticity of microglial cells in transgenic rat brain expressing human truncated tau protein. Intraneuronal expression of human truncated tau induces neurofibrillary degeneration. Injured neurons drive resting microglia to become reactive microglia that transform into brain phagocytic microglia: brain macrophages. At this stage, microglia lose contact inhibition and begin to fuse with each other, forming small clusters. Morphological activation of microglia is accompanied with upregulation of several immunological markers,

including integrins CD11a, CD11b, CD11c and CD18; lymphocytic antigen CD4; leukocyte common antigen CD45; and lysosomal glycoprotein CD68 (colour dots). In the late stage of neurodegeneration, bloodborne leukocytes (mainly monocytes and partially dendritic cells) infiltrate the brain parenchyma and participate in the brain's immune response.

phenotype. A significant impact of the genetic background on survival, behaviour, amyloid levels and plaque burden in the brains of amyloid transgenic mice has been observed [58]. To identify genetic modifiers on the tau neurodegenerative and neuroinflammatory cascades, we used transgenic lines expressing human truncated tau protein in either the spontaneously hypertensive rat (SHR) or on the Wistar-Kyoto (WKY) genetic background [33]. The SHR background was chosen for its propensity to develop major risk factors for $\mathrm{AD}$, such as hypertension, insulin 

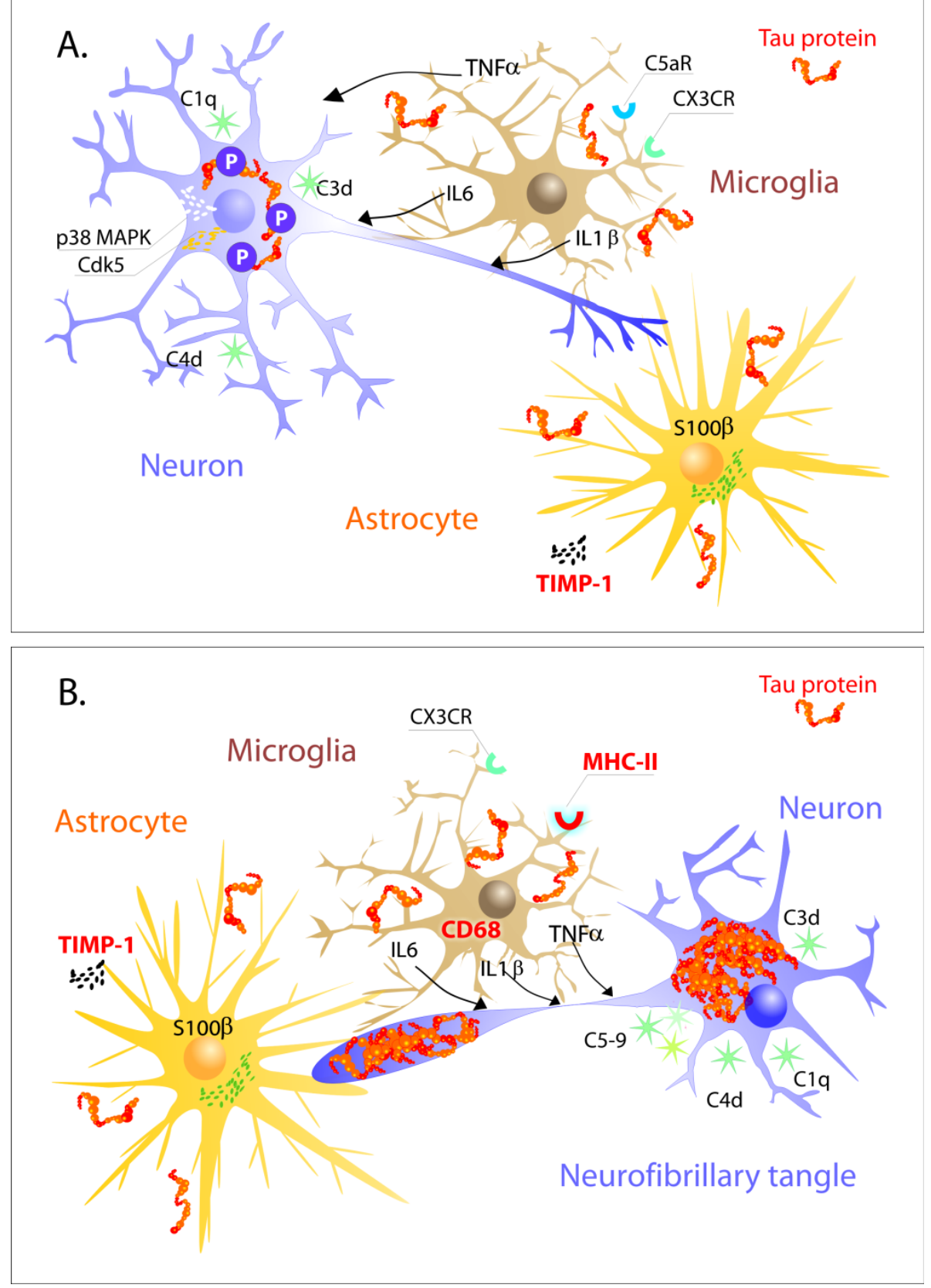

Figure 4 Tau neuroinflammatory cascade. In early stages of tau structural metamorphosis, some proinflammatory cytokines (IL-1, IL6 and TNF$\alpha$ ) and chemokines (fractalkine) can modify tau phosphorylation patterns and thus change the structure and function of tau protein. The major sources of proinflammatory cytokines are activated microglia and astrocytes. Glial cells can be activated by different inducers, including misfolded tau protein. At this stage, however, the phosphorylated tau protein would not necessarily aggregate into the filamentous structures (A). In later stages, when misfolded hyperphosphorylated tau proteins form mature NFTs, inflammation could either accelerate or modify tangle formation. Several components of the brain's immune system, including cytokines and proteins of the complement pathway, have been shown to be involved in the molecular dialogue between activated glial cells and tangle-bearing neurons (B).

resistance and metabolic syndrome. We have shown that tau neurodegeneration can induce inflammatory responses mediated by reactive microglia $[32,33]$. Activated microglia underwent a transformation from resting to reactive and phagocytic states accompanied by upregulation of several immunologically important molecules, including CD11a, CD11b, CD11c, CD18, CD4, CD45 and CD68. Reactive microglia were frequently distributed around axonal lesions and in close proximity to NFTs. Simultaneously, the innate immune brain response promoted the influx of 
bloodborne leukocytes (mainly monocytes and partially dendritic cells) into the brain parenchyma (Figure 3) [32]. The WKY rats, which were used as normotensive controls, also developed neurofibrillary degeneration accompanied by neuroinflammation. Moreover, they displayed significantly lower final NFT loads than their SHR transgenic counterparts. We also observed that microglial responses showed a striking difference between transgenic lines. In SHR transgenic rats, a limited number of microglia (less than $2 \%$ ) expressed major histocompatibility complex class II (MHCII) molecules, despite having a robust phagocytic phenotype. In contrast, almost $20 \%$ of the microglia expressed MHCII molecules in WKY transgenic rat brain. Moreover, they displayed a considerably lower extent of phagocytic morphology [33]. These findings suggest that the brain immune response determined by genetic environment could be a potent disease modifier of neurofibrillary degeneration. Whereas tau neurofibrillary degeneration correlates with disease progression, neuroinflammation seems to regulate the resistance or susceptibility to neurodegeneration.

\section{When the victim becomes the wrongdoer: misfolded tau as a potent activator of the brain's immune response}

It has been hypothesized that endogenous intracellular tau may be released into the extracellular space upon neuron degeneration [59]. However, very recent data indicate that tau could be released into the brain interstitial fluid (ISF) in the absence of neurodegeneration. Moreover, the concentration of tau can be significantly higher in the ISF than in the cerebrospinal fluid [60]. These findings strongly point out that intracellular tau is released into the brain's extracellular environment.

Numerous researchers have claimed that soluble extracellular tau may promote neurotoxicity $[59,61,62]$, increase intracellular calcium through neuronal M1 and M3 muscarinic receptors [61], cause synaptic impairment [63] and induce blood-brain barrier damage [64]. We have recently found that misfolded truncated tau is able to activate the innate immune response via MAPK pathways. We reported that purified recombinant soluble truncated tau caused the release of NO, proinflammatory cytokines (IL-1 $\beta$, IL- 6 and TNF- $\alpha$ ) and tissue inhibitor of metalloproteinase 1 from mixed astrogliamicroglia cultures [65]. It is important to note that the active concentration of misfolded tau was in the range of 0.1 and $1 \mu \mathrm{M}$. Similarly, other disease-modified neuronal proteins such as $A \beta$ and $\alpha$-synuclein are able to activate microglial cells in the same concentration range (A $\beta 0.2$ to $1 \mu \mathrm{M}$ and $\alpha$-synuclein 0.1 to $1 \mu \mathrm{M}$ ) [66-70].

Transcriptomic analysis revealed that truncated tau increased mRNA levels of three MAPKs: c-Jun N-terminal kinase, extracellular-signal-regulated kinase 1 and p38 $\beta$, which in turn led to the activation of transcription factors such as activator protein 1 and NF- $\kappa$ B. The activation of transcription factors ultimately resulted in enhanced expression of IL-1 $\beta$, IL- 6 , TNF- $\alpha$ and NO [65]. These results, together with previously published data, demonstrate that misfolded tau protein is able to induce an innate immune response through a MAPK pathway and that simultaneously tau's pathological transformation can be regulated by activated glial cells via the same pathway.

\section{Conclusions}

On the basis of our current body of knowledge, we can conclude that neuroinflammation is a potent modifier of the tau neurodegenerative cascade and, to some extent, can determine the vulnerability of the brain to $\mathrm{AD}$ neurodegeneration. The inflammatory response can affect the tau pathological metamorphosis, increasing tau phosphorylation via MAPK kinase pathways and accelerating tangle formation. Extracellular tau can induce immune responses via a MAPK kinase pathway as well (Figure 4). Taken together, these results suggest that tau is located at the crossroad of the neurodegenerative and neuroinflammatory cascades. This is the reason to believe that targeted immunomodulatory therapeutic approaches can significantly modify the tau neurodegenerative cascade and may ultimately have a direct impact on the clinical course of $\mathrm{AD}$.

\section{Abbreviations}

IL: interleukin; NF-kB: nuclear factor $\mathrm{kB}$; TNF-a: tumour necrosis factor a.

\section{Acknowledgements}

This work was supported by Axon Neuroscience and research grants VEGA 2/0144/08, VEGA 2/0067/10, LPP-0039-09 and APW 0631-07.

\section{Author details}

${ }^{1}$ Institute of Neuroimmunology, 84510 Bratislava, Slovak Republic. ${ }^{2}$ Axon Neuroscience GmbH, 1030 Vienna, Austria. ${ }^{3}$ Small Animals Clinic, University of Veterinary Medicine and Pharmacy, Komenskeho 73, 04181 Kosice, Slovakia.

\section{Authors' contributions}

$\mathrm{NZ}, \mathrm{ZK}, \mathrm{SJ}, \mathrm{OB}, \mathrm{AM}$ and PN each wrote the individual sections in sequential order in the manuscript. DO created all the figures and illustrations. MN coordinated all efforts, made decisions about content and shaped the final form of the manuscript. All authors read and approved the final manuscript.

\section{Competing interests}

The authors declare that they have no competing interests.

Received: 19 October 2011 Accepted: 7 March 2012

Published: 7 March 2012

\section{References}

1. Grundke-lqbal I, lqbal K, Quinlan M, Tung YC, Zaidi MS, Wisniewski HM: Microtubule-associated protein tau: a component of Alzheimer paired helical filaments. J Biol Chem 1986, 261:6084-6089.

2. Grundke-labal I, labal K, Tung YC, Quinlan M, Wisniewski HM, Binder LI: Abnormal phosphorylation of the microtubule-associated protein tau (tau) in Alzheimer cytoskeletal pathology. Proc Natl Acad Sci USA 1986, 83:4913-4917. 
3. Glenner GG, Wong CW: Alzheimer's disease and Down's syndrome: sharing of a unique cerebrovascular amyloid fibril protein. Biochem Biophys Res Commun 1984, 122:1131-1135.

4. Wischik CM, Novak M, Thøgersen HC, Edwards PC, Runswick MJ, Jakes R, Walker JE, Milstein $C$, Roth $M$, Klug A: Isolation of a fragment of tau derived from the core of the paired helical filament of Alzheimer disease. Proc Natl Acad Sci USA 1988, 85:4506-4510.

5. Wischik CM, Novak M, Edwards PC, Klug A, Tichelaar W, Crowther RA: Structural characterization of the core of the paired helical filament of Alzheimer disease. Proc Natl Acad Sci USA 1988, 85:4884-4888.

6. Braak H, Braak E: Neuropathological stageing of Alzheimer-related changes. Acta Neuropathol 1991, 82:239-259.

7. Dickson DW: Neuropathological diagnosis of Alzheimer's disease: a perspective from longitudinal clinicopathological studies. Neurobiol Aging 1997, 18(4 Suppl):S21-S26.

8. Iqbal K, Grundke-lqbal I: Alzheimer's disease, a multifactorial disorder seeking multitherapies. Alzheimers Dement 2010, 6:420-424.

9. Akiyama H, Arai T, Kondo H, Tanno E, Haga C, Ikeda K: Cell mediators of inflammation in the Alzheimer disease brain. Alzheimer Dis Assoc Disord 2000, 14:47-53.

10. Mrak RE, Griffin WS: The role of activated astrocytes and of the neurotrophic cytokine S100B in the pathogenesis of Alzheimer's disease. Neurobiol Aging 2001, 22:915-922.

11. Eikelenboom P, Veerhuis R, Scheper W, Rozemuller AJM, van Gool W, Hoozemans J: The significance of neuroinflammation in understanding Alzheimer's disease. J Neural Transm 2006, 113:1685-1695.

12. Walsch S, Aisen P: Inflammatory processes in Alzheimer's disease. Expert Rev Neurotherapeutics 2004, 4:793-798.

13. Grundke-labal I, Fleming J, Tung YC, Lassmann H, labal K, Joshi JG: Ferritin is a component of the neuritic (senile) plaque in Alzheimer dementia. Acta Neuropathol 1990, 81:105-110.

14. Sheffield LG, Marquis JG, Berman NE: Regional distribution of cortical microglia parallels that of neurofibrillary tangles in Alzheimer's disease. Neurosci Lett 2000, 285:165-168

15. Overmyer M, Helisalmi S, Soininen H, Laakso M, Riekkinen P, Alafuzoff I: Reactive microglia in aging and dementia: an immunohistochemical study of postmortem human brain tissue. Acta Neuropathol 1999, 97:383-392.

16. Sheng JG, Mrak RE, Griffin WS: Glial-neuronal interactions in Alzheimer disease: progressive association of $\mathrm{IL}^{-1 \mathrm{a}^{+}}$microglia and $\mathrm{S} 100 \mathrm{\beta}^{+}$ astrocytes with neurofibrillary tangle stages. I Neuropathol Exp Neurol 1997, 56:285-290.

17. Cras P, Kawai M, Siedlak S, Perry G: Microglia are associated with the extracellular neurofibrillary tangles of Alzheimer disease. Brain Res 1991, 558:312-314.

18. DiPatre PL, Gelman BB: Microglial cell activation in aging and Alzheimer disease: partial linkage with neurofibrillary tangle burden in the hippocampus. J Neuropathol Exp Neurol 1997, 56:143-149.

19. Probst A, Ulrich J, Heitz PU: Senile dementia of Alzheimer type: astroglial reaction to extracellular neurofibrillary tangles in the hippocampus: an immunocytochemical and electron-microscopic study. Acta Neuropathol 1982, 57:75-79.

20. McGeer PL, Akiyama H, Itagaki S, McGeer EG: Immune system response in Alzheimer's disease. Can J Neurol Sci 1989, 16(4 Suppl):516-527.

21. Shen Y, Lue L, Yang L, Roher A, Kuo Y, Strohmeyer R, Goux WJ, Lee V, Johnson GV, Webster SD, Cooper NR, Bradt B, Rogers J: Complement activation by neurofibrillary tangles in Alzheimer's disease. Neurosci Lett 2001, 305:165-168

22. Schwab C, Steele JC, McGeer PL: Neurofibrillary tangles of Guam parkinson-dementia are associated with reactive microglia and complement proteins. Brain Res 1996, 707:196-205.

23. Ishizawa K, Dickson DW: Microglial activation parallels system degeneration in progressive supranuclear palsy and corticobasal degeneration. J Neuropathol Exp Neurol 2001, 60:647-657.

24. Gerhard A, Trender-Gerhard I, Turkheimer F, Quinn NP, Bhatia KP, Brooks DJ: In vivo imaging of microglial activation with $\left[{ }^{11} \mathrm{C}\right](\mathrm{R})-\mathrm{PK} 11195 \mathrm{PET}$ in progressive supranuclear palsy. Mov Disord 2006, 21:89-93.

25. Gerhard A, Watts J, Trender-Gerhard I, Turkheimer F, Banati RB, Bhatia K, Brooks DJ: In vivo imaging of microglial activation with $\left[{ }^{11} \mathrm{C}\right](\mathrm{R})$ PK11195 PET in corticobasal degeneration. Mov Disord 2004, 19:1221-1226.
26. Henkel K, Karitzky J, Schmid M, Mader I, Glatting G, Unger JW, Neumaier B, Ludolph AC, Reske SN, Landwehrmeyer GB: Imaging of activated microglia with PET and $\left[{ }^{11} \mathrm{C}\right] \mathrm{PK} 11195$ in corticobasal degeneration. Mov Disord 2004, 19:817-821.

27. Paulus W, Bancher C, Jellinger K: Microglial reaction in Pick's disease. Neurosci Lett 1993, 161:89-92.

28. Bellucci A, Westwood AJ, Ingram E, Casamenti F, Goedert M, Spillantini MG: Induction of inflammatory mediators and microglial activation in mice transgenic for mutant human P301S tau protein. Am J Pathol 2004, 165:1643-1652.

29. Yoshiyama Y, Higuchi M, Zhang B, Huang SM, Iwata N, Saido TC, Maeda J, Suhara T, Trojanowski JQ, Lee VM: Synapse loss and microglial activation precede tangles in a P301S tauopathy mouse model. Neuron 2007, 53:337-351.

30. Ikeda M, Shoji M, Kawarai T, Kawarabayashi T, Matsubara E, Murakami T, Sasaki A, Tomidokoro Y, Ikarashi Y, Kuribara H, Ishiguro K, Hasegawa M, Yen SH, Chishti MA, Harigaya Y, Abe K, Okamoto K, St George-Hyslop P, Westaway D: Accumulation of filamentous tau in the cerebral cortex of human tau R406W transgenic mice. Am J Pathol 2005, 166:521-531.

31. Sasaki A, Kawarabayashi T, Murakami T, Matsubara E, Ikeda M, Hagiwara H, Westaway D, George-Hyslop PS, Shoji M, Nakazato Y: Microglial activation in brain lesions with tau deposits: comparison of human tauopathies

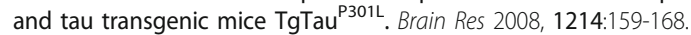

32. Zilka N, Stozicka Z, Kovac A, Pilipcinec E, Bugos O, Novak M: Human misfolded truncated tau protein promotes activation of microglia and leukocyte infiltration in the transgenic rat model of tauopathy. J Neuroimmunol 2009, 209:16-25.

33. Stozicka Z, Zilka N, Novak P, Kovacech B, Bugos O, Novak M: Genetic background modifies neurodegeneration and neuroinflammation driven by misfolded human tau protein in rat model of tauopathy: implication for immunomodulatory approach to Alzheimer's disease. J Neuroinflammation 2010, 7:64.

34. Filipcik P, Zilka N, Bugos O, Kucerak J, Koson P, Novak P, Novak M: First transgenic rat model developing progressive cortical neurofibrillary tangles. Neurobiol Aging , doi:10.1016/j.neurobiolaging.2010.10.015

35. Zilka N, Filipcik P, Koson P, Fialova L, Skrabana R, Zilkova M, Rolkova G, Kontsekova E, Novak M: Truncated tau from sporadic Alzheimer's disease suffices to drive neurofibrillary degeneration in vivo. FEBS Lett 2006, 580:3582-3588.

36. Mackenzie IRA: Anti-inflammatory drugs and Alzheimer-type pathology in aging. Neurology 2000, 54:732-734.

37. McGeer PL, McGeer EG: NSAIDs and Alzheimer disease: epidemiological, animal model and clinical studies. Neurobiol Aging 2007, 28:639-647.

38. McGeer PL, Schulzer M, McGeer EG: Arthritis and anti-inflammatory agents as possible protective factors for Alzheimer's disease: a review of 17 epidemiologic studies. Neurology 1996, 47:425-432.

39. Zandi PP, Breitner JC: Do NSAIDs prevent Alzheimer's disease? And, if so, why? The epidemiological evidence. Neurobiol Aging 2001, 22:811-817.

40. Aisen PS, Davis KL, Berg JD, Schafer K, Campbell K, Thomas RG, Weiner MF, Farlow MR, Sano M, Grundman M, Thal L: A randomized controlled trial of prednisone in Alzheimer's disease: Alzheimer's Disease Cooperative Study. Neurology 2000, 54:588-41.

41. Aisen PS, Schafer KA, Grundman M, Pfeiffer E, Sano M, Davis KL, Farlow MR, Jin S, Thomas RG, Thal LJ: Alzheimer's disease cooperative study: effects of rofecoxib or naproxen vs placebo on Alzheimer disease progression: a randomized controlled trial. JAMA 2003, 289:2819-2826.

42. Reines SA, Block GA, Morris JC, Liu G, Nessly ML, Lines CR, Norman BA, Baranak CC: Rofecoxib protocol 091 study group: rofecoxib: no effect on Alzheimer's disease in a 1-year, randomized, blinded, controlled study. Neurology 2004, 62:66-71.

43. de Jong $D$, Jansen $R$, Hoefnagels $W$, Jellesma-Eggenkamp $M$, Verbeek $M$, Borm G, Kremer B: No effect of one-year treatment with indomethacin on Alzheimer's disease progression: a randomized controlled trial. PLOS One 2008, 3:e1475.

44. Sonnen JA, Larson EB, Walker RL, Haneuse S, Crane PK, Gray SL, Breitner JC, Montine TJ: Nonsteroidal anti-inflammatory drugs are associated with increased neuritic plaques. Neurology 2010, 75:1203-1210.

45. Beeri MS, Schmeidler J, Lesser GT, Maroukian M, West R, Leung S, Wysocki M, Perl DP, Purohit DP, Haroutunian V: Corticosteroids, but not NSAIDs, are associated with less Alzheimer neuropathology. Neurobiol Aging, doi:10.1016/j.neurobiolaging.2011.02.011. 
46. Streit WJ, Sammons NW, Kuhns AJ, Sparks DL: Dystrophic microglia in the aging human brain. Glia 2004, 45:208-212

47. Streit WJ: Microglial senescence: does the brain's immune system have an expiration date? Trends Neurosci 2006, 29:506-510.

48. Streit WJ, Braak H, Xue QS, Bechmann I: Dystrophic (senescent) rather than activated microglial cells are associated with tau pathology and likely precede neurodegeneration in Alzheimer's disease. Acta Neuropathol 2009, 118:475-485.

49. Li Y, Liu L, Barger SW, Griffin WS: Interleukin-1 mediates pathological effects of microglia on tau phosphorylation and on synaptophysin synthesis in cortical neurons through a p38-MAPK pathway. J Neurosci 2003, 23:1605-1611.

50. Quintanilla RA, Orellana DI, Gonzalez-Billault C, Maccioni RB: Interleukin-6 induces Alzheimer-type phosphorylation of tau protein by deregulating the cdk5/p35 pathway. Exp Cell Res 2004, 295:245-257.

51. Saez TE, Pehar M, Vargas M, Barbeito L, Maccioni RB: Astrocytic nitric oxide triggers tau hyperphosphorylation in hippocampal neurons. In Vivo 2004, 18:275-280.

52. Lee DC, Rizer J, Selenica ML, Reid P, Kraft C, Johnson A, Blair L, Gordon MN, Dickey CA, Morgan D: LPS-induced inflammation exacerbates phosphotau pathology in rTg4510 mice. J Neuroinflammation 2010, 7:56.

53. Kitazawa M, Oddo S, Yamasaki TR, Green KN, LaFerla FM: Lipopolysaccharide-induced inflammation exacerbates tau pathology by a cyclin-dependent kinase 5-mediated pathway in a transgenic model of Alzheimer's disease. J Neurosci 2005, 25:8843-8853.

54. Bhaskar K, Konerth M, Kokiko-Cochran ON, Cardona A, Ransohoff RM, Lamb BT: Regulation of tau pathology by the microglial fractalkine receptor. Neuron 2010, 68:19-55.

55. Janelsins MC, Mastrangelo MA, Park KM, Sudol KL, Narrow WC, Oddo S, LaFerla FM, Callahan LM, Federoff HJ, Bowers WJ: Chronic neuron-specific tumor necrosis factor-a expression enhances the local inflammatory environment ultimately leading to neuronal death in $3 \times \mathrm{Tg}-\mathrm{AD}$ mice. Am J Pathol 2008, 173:1768-1782.

56. Gorlovoy P, Larionov S, Pham TTH, Neumann H: Accumulation of tau induced in neurites by microglial proinflammatory mediators. FASEB J 2009, 23:2502-2513.

57. Lee S, Varvel NH, Konerth ME, Xu G, Cardona AE, Ransohoff RM, Lamb BT: CX3CR1 deficiency alters microglial activation and reduces $\beta$-amyloid deposition in two Alzheimer's disease mouse models. Am J Pathol 2010 177:2549-2562.

58. Ryman D, Lamb BT: Genetic and environmental modifiers of Alzheimer's disease phenotypes in the mouse. Curr Alzheimer Res 2006, 3:465-473.

59. Gómez-Ramos A, Díaz-Hernández M, Cuadros R, Hernández F, Avila J: Extracellular tau is toxic to neuronal cells. FEBS Lett 2006, 580:4842-4850.

60. Yamada K, Cirrito JR, Stewart FR, Jiang H, Finn MB, Holmes BB, Binder LI, Mandelkow EM, Diamond MI, Lee VM, Holtzman DM: In vivo microdialysis reveals age-dependent decrease of brain interstitial fluid tau levels in P301S human tau transgenic mice. J Neurosci 2011, 31:13110-13117.

61. Gómez-Ramos A, Díaz-Hernández M, Rubio A, Miras-Portugal MT, Avila J: Extracellular tau promotes intracellular calcium increase through M1 and M3 muscarinic receptors in neuronal cells. Mol Cell Neurosci 2008, 37:673-681.

62. Gómez-Ramos A, Díaz-Hernández M, Rubio A, Díaz-Hernández Jl, MirasPortugal MT, Avila J: Characteristics and consequences of muscarinic receptor activation by tau protein. Eur Neuropsychopharmacol 2009, 19:708-717.

63. Moe JG, Chatterjee I, Davidowitz EJ, Arancio O: Modulation of synaptic function by extracellular tau enriched in oligomers [abstract]. Alzheimers Dement 2009, 5(4 Suppl):P499.

64. Kovac A, Zilkova M, Deli MA, Zilka N, Novak M: Human truncated tau is using a different mechanism from amyloid- $\beta$ to damage the blood-brain barrier. J Alzheimers Dis 2009, 18:897-906.

65. Kovac A, Zilka N, Kazmerova Z, Cente M, Zilkova M, Novak M: Misfolded truncated protein $\tau$ induces innate immune response via MAPK pathway. J Immunol 2011, 187:2732-2739.

66. Paresce DM, Ghosh RN, Maxfield FR: Microglial cells internalize aggregates of the Alzheimer's disease amyloid $\beta$-protein via a scavenger receptor. Neuron 1996, 17:553-565.

67. Shimizu E, Kawahara K, Kajizono M, Sawada M, Nakayama H: IL-4-induced selective clearance of oligomeric -amyloid peptide ${ }_{1-42}$ by rat primary type 2 microglia. J Immunol 2008, 181:6503-6513.
68. Yang CN, Shiao YJ, Shie F, Guo BS, Chen PH, Cho CY, Chen YJ, Huang FL, Tsay $\mathrm{HJ}$ : Mechanism mediating oligomeric $A \beta$ clearance by naïve primary microglia. Neurobiol Dis 2011, 42:221-230.

69. Thomas MP, Chartrand K, Reynolds A, Vitvitsky V, Banerjee R, Gendelman HE: Ion channel blockade attenuates aggregated a synuclein induction of microglial reactive oxygen species: relevance for the pathogenesis of Parkinson's disease. J Neurochem 2007, 100:503-519.

70. Park JY, Paik SR, Jou I, Park SM: Microglial phagocytosis is enhanced by monomeric a-synuclein, not aggregated a-synuclein: implications for Parkinson's disease. Glia 2008, 56:1215-1223.

doi:10.1186/1742-2094-9-47

Cite this article as: Zilka et al:: Who fans the flames of Alzheimer's disease brains? Misfolded tau on the crossroad of neurodegenerative and inflammatory pathways. Journal of Neuroinflammation 2012 9:47.

\section{Submit your next manuscript to BioMed Central and take full advantage of:}

- Convenient online submission

- Thorough peer review

- No space constraints or color figure charges

- Immediate publication on acceptance

- Inclusion in PubMed, CAS, Scopus and Google Scholar

- Research which is freely available for redistribution

Submit your manuscript a www.biomedcentral.com/submit
C Biomed Central 